\title{
Effectiveness of Health Education on Knowledge Regarding Diseases Preventable Vaccines Among Mothers of Under Five Year Children
}

\author{
Ayesha Qundeel $^{1^{*}} \quad$ Muhammad Hussain $^{2} \quad$ Iram Majeed ${ }^{2} \quad$ Muhammad Afzal $^{3}$ \\ Syed Amir Gilani ${ }^{4}$ \\ 1.BS Nursing, The University of Lahore, PO box 54000, Lahore, Pakistan \\ 2.Lecturer, the University of Lahore, PO box 54000, Lahore, Pakistan \\ 3.Associate Professor, The University of Lahore, PO box 54000, Lahore, Pakistan 4.Professor, The University of
} Lahore, PO box 54000, Lahore, Pakistan

\begin{abstract}
Introduction: Childhood is a significant period in the cycle of human life. Advancement of wellbeing and counteractive action of sickness is important for this stage. Communicable diseases are a high hazard for the childhood time frame. In the creating nations avoidance of illnesses by immunization right off the bat in adolescence is as yet a major issue, 5 million are biting the dust and 5 million are handicapped through irresistible malady every year from the get-go in childhood Methods: A Quasi-experimental study with pre/post-intervention phases using the quantitative method of data collection conducted among mothers in rural community, Lahore, to determine Effectiveness of health education on knowledge regarding diseases preventable vaccines among mothers of under five year children. The sample size was 70 by using convenient sampling technique. SPSS version 21 statistical software was used for data analysis and a $95 \%$ confidence interval was used in this study with a $\mathrm{P} \leq 0.05$ considered statistically significant. Results: Results showed that the total mean of knowledge before intervention was 10.74 but after intervention, the total mean of knowledge was 23.02. The structured teaching programme has increased the knowledge of mothers regarding diseases preventable vaccines of under five year children. Conclusions: This study has demonstrated the structured teaching programme in community is much effective to improve the knowledge of mothers regarding diseases preventable vaccines of under five year children. The mean knowledge score on behavioral problems increased significantly after the teaching sessions.
\end{abstract}

Keywords- Effectiveness, Structured teaching programme, Knowledge, diseases preventable vaccines.

DOI: $10.7176 / \mathrm{JHMN} / 68-04$

Publication date: November $30^{\text {th }} 2019$

\section{Introduction}

Childhood is a significant period in the cycle of human life. Advancement of wellbeing and counteractive action of sickness is important for this stage (Varghese et al., 2016).

Vaccination is the best apparatus to kill and control dangerous illnesses which are irresistible and furthermore diminishing 2 to 3 million passing's consistently. An expected 22 million newborn children are feeling the loss of the fundamental immunization around the world (Awoh \& Plugge, 2016).

Today the vast majority of the guardians have never observed the irritating outcomes of those diseases which are immunization preventable have on a family or community. Diseases preventable vaccines are inconsistently happening in the nation that is the reason it is essential to proceed with the assurance of child by an immunization. Vaccination is the most ideal path by which guardians can shield their children's from numerous hurtful ailments. Particularly in newborn children and little children's, vaccine preventable diseases are intense and may prompt hospitalization or even to death (Alenazi et al., 2014).

In Pakistan there were 198 polio cases in 2011, 58 in 2012 and 83 cases were accounted in 2013. Pakistan has additionally observed an ascent in measles cases in recent years. In 2011, 64 child passed, and in 2012 the number expanded to 306, with Sindh as the most influenced area. It is accounted for that there were 192 passing's from measles in the Punjab territory of Pakistan in 2013 (Bugvi et al., 2014).

The yearly health report of the Pakistan Medical Association (PMA) for the year 2011, that show one child kicks the bucket each moment from communicable diseases. The report likewise uncovers that consistently around 400,000 newborn children pass on in the first year of their life (Asim, Mahmood, \& Sohail, 2015).

Parents' knowledge about vaccine schedules is a predictor factor for children's immunization status (Animaw, Taye, Merdekios, Tilahun, \& Ayele, 2014) .

The negative demeanors among guardians are fundamental because of an absence of information about the significance and safety of vaccines (Esposito, Principi, Cornaglia, \& Group, 2014).

Numerous investigations have discovered that guardians' absence of information about immunizations is an issue that prompts low vaccination inclusion (Esposito et al., 2014).

Improving the mother's education level is very important, to empower the first care provider of child in the community. However, health educational messages related to the vaccination of child decrease the mortality rate 
in children (Shaikh, Memon, \& Ahmed, 2014).

Teaching mothers whose children's are in danger of not finishing the immunization calendar is a significant methodology to improve vaccination inclusion. An instructive program about the significance of vaccination is required, particularly for guardians with a lower instructive level, so as to improve the immunization rate (Al-Lela et al., 2014).

Knowledge is enhanced with reinforcement. Mothers are the essential parental figures of children's and they are the one effectively associated with the health and sickness of the children. On the off chance that the mothers are taught on the wellbeing parts of children's, numerous horrendous ailments can be averted in the nation (Umarani, 2017).

\section{Literature Review}

As stated by Alenazi et al in 2014 that parents' knowledge about vaccination and their attitudes towards them are likely influence uptake. Mothers' knowledge about vaccination was found to be quite low and their educational status was significantly associated with child's coverage. Negative attitude, for example mothers fear from vaccination, was found to be significantly affected the vaccination status of their children (Alenazi et al.).

A community-based intervention study from Karachi Pakistan had also proved that health education for mothers of child would positively improve the health of their child by building their knowledge about health (Ali, Pongpanich, \& Kumar, 2015).

In opinion of Harvey, Reissland, \& Mason that educational interventions were very effective in low and middle-income countries $(95 \%)$ for vaccination, these interventions increase the mothers knowledge about vaccination (Harvey, Reissland, \& Mason, 2015).

As described by Awoh \& Plugge, 2016 less than one third of the studied mothers had good knowledge score related to children vaccination. The results of the study may be due to the low level of awareness, lack of educational program in rural areas and their positive attitude toward vaccination may be due to that parents knew that vaccination was mandatory and required for school registration (Awoh \& Plugge, 2016).

The study is conducted by (Awadh et al., 2014) on an educational seminar to improve parents' knowledge about vaccination. This study demonstrated that providing a one-hour educational seminar to parents is an effective and practical strategy to improve parents' knowledge about childhood immunization (Awadh et al., 2014).

According to study of Younus, Ijaz, \& Mateen in 2017 on the factors associated with delayed or nonimmunization in children. The results indicated that educating mothers about the diseases preventable vaccines may be highly effective in increasing the immunization coverage (Younus, Ijaz, \& Mateen, 2017).

A study conducted by Umarani, 2017 about the effectiveness of planned teaching programme on vaccination. The findings of study revealed that the post-test knowledge score $26.53 \%$ was higher than the pre-test knowledge score $13.5 \%$. Therefore, planned teaching programme was found to be an effective media for educating mothers regarding importance of vaccination (Umarani, 2017).

\section{Methodology}

Quasi-experimental with pre and post-intervention phases using the quantitative method of data collection. Data was collected from 70 women using convenient sampling technique. A well adopted questionnaire was used, Participants were well informed. Data was analysed through SPSS 21. The study was 4-5 month (September 2018 to December 2018).

\section{Results}

This section presents the outcomes of the study, Profile of the respondents and outcome of questionnaire regarding knowledge regarding Diseases preventable vaccines and also represents the result of paired t-test comparison before and after intervention and results for objective of this study "To evaluate the effectiveness of structured teaching programme on mother's knowledge regarding Diseases preventable vaccines under five year children. According to this table total of 50 respondents participated in the study. It indicates that the majority of the participants were females $(100 \%)$.The maximum age of respondents was belong to $30-34$ age group $(60 \%)$ and the minimum $25-29$ age group $(40 \%)$. 
Table 1: Demographic Characteristic of participants.

\begin{tabular}{|l|l|l|l|l|}
\hline Table No: 1 Demographic Characteristic & N & $\%$ \\
\hline S\# & Demographic Characteristic & 70 & \multicolumn{2}{|c|}{ GENDER } \\
\hline & & \multicolumn{2}{|c|}{$100 \%$} \\
\hline $\mathbf{1}$ & Female & 70 & \multicolumn{2}{|c|}{ Qualification } \\
\hline & Male & 0 & 0 & $30.0 \%$ \\
\hline $\mathbf{2}$ & Non educated & 21 & $65.7 \%$ \\
\hline & Primary & 46 & $1.4 \%$ \\
\hline & Middle & 1 & $2.9 \%$ \\
\hline $\mathbf{3}$ & Secondary & 2 & \multicolumn{2}{|c|}{ Age Group } \\
\hline & & & $15.7 \%$ \\
\hline & 22-25year & 11 & $18.6 \%$ \\
\hline & $26-29 y e a r$ & 13 & $60.0 \%$ \\
\hline & 30-34year & 42 & 4 & $5.7 \%$ \\
\hline
\end{tabular}

According to this table total of 70 respondents participated in the study. It indicates that the majority of the participants were females (100\%). The minimum age of respondents was $25-29$ age group (40\%) and the maximum $30-34$ age group $(60 \%)$.

Table 2: Paired Samples Statistics.

\begin{tabular}{|c|c|c|c|c|}
\hline \multicolumn{5}{|c|}{ Table No: 2 Paired Samples Statistics } \\
\hline & Mean & N & SD & SE \\
\hline Pre intervention & 10.74 & 70 & 2.54 & .303 \\
Post intervention & 23.02 & 70 & 2.41 & .288 \\
\hline
\end{tabular}

Following table and figure shows the mean, standard deviation, standard error of mean and mean percentages of pre-post score of knowledge and practice, illustrate that the knowledge and practice score mean improved in post intervention phase. That was $10.74 \%$ pre-test knowledge and improved at $23.02 \%$ level in post intervention phase.

Table No. 3 Paired Samples Test

\begin{tabular}{|c|c|c|c|c|c|c|c|c|}
\hline \multicolumn{9}{|c|}{ Table No: 3 Paired Samples Test } \\
\hline & \multicolumn{5}{|c|}{$\begin{array}{l}\text { Paired } \\
\text { Differences } \\
\end{array}$} & \multirow{4}{*}{$\begin{array}{l}\mathrm{t} \\
27.75\end{array}$} & \multirow{4}{*}{$\begin{array}{l}\text { DF } \\
69\end{array}$} & \multirow[t]{3}{*}{ Sig.(2-tailed) } \\
\hline & \multirow[t]{2}{*}{ Mean } & \multirow[t]{2}{*}{$\mathrm{SD}$} & \multirow[t]{2}{*}{ S.E } & \multicolumn{2}{|c|}{$95 \%$ Confidence Interval } & & & \\
\hline & & & & Lower & Upper & & & \\
\hline Pre-Post & -12.28 & 3.70 & .442 & -13.16 & -11.40 & & & .00 \\
\hline
\end{tabular}

\section{Discussion}

All the respondents in this study were females, $100 \%$, a similar study carried out in Ilorin reported the same finding of predominantly female respondents of $99.6 \%$ (T. Afolaranmi, Hassan, Bello, \& Misari, 2015).

The mean age of the respondents was $32.07 \pm 8.71$ years. This was same as the findings of studies were conducted among mothers in primary health centre of Nigeria and Malaysia. This similarity indicated that the majority of the mothers were middle-aged (Sharif et al., 2015).

The result of pre and post-test of intervention session is 10.74 and 23.02 respectively. Mean knowledge score of pre-test and post-test indicating the effectiveness of health education on diseases preventable vaccines among mothers of under five year children. The statistical paired t-test shows the significant result in enhancing the knowledge scores between pre-test and post-test for all the aspect under study.

Present study findings showed strong positive significant of health education on diseases preventable vaccines among mothers improve the knowledge of mothers. Consistent with our findings another study also showed that educating mothers whose children are not completing the immunization schedule is an important strategy to improve immunization coverage. An educational programme about the importance of immunization is needed, especially for parents with a lower educational level in order to improve the immunization rate (Al-Lela et al., 2014).

\section{ACKNOWLEDGEMENT}

I would like to thank the following people who in many ways contributed to this piece of work. First and foremost, I would like to thank Mr. Muhammad Afzal (The Principal of Lahore School of Nursing) who allowed me to do 
this study and guided me. I would thank to Sir Muhammad Husain for being my preceptor and for being the greatest inspiration for my work when I had no idea to perform a research work. I am indebted to his and I admire the way in which he explained very difficult concepts in very simple ways. He is very helpful in giving me suggestions. I would like to thank my parents who gave me emotional and financial support during this study all the participants and my colleagues. Their support and prayers made this study possible. It is a great pleasure to have wonderful parents. I also thank the management of University of Lahore.

\section{References}

Ahmed, V., \& Ahmed, S. (2014). Poverty and social impact analysis of expanded program on immunization in Pakistan: Sustainable Development Policy Institute Islamabad.

Ababio, P. F., \& Lovatt, P. (2015). A review on food safety and food hygiene studies in Ghana. Food Control, 47, 92-97.

Adebukola, O. C., Opeyemi, A. O., \& Ayodeji, A. I. (2015). Knowledge of food borne infection and food safety practices among local food handlers in Ijebu-Ode Local Government Area of Ogun State. Journal of Public Health and Epidemiology, 7(9), 268-273.

Al-Lela, O. Q. B., Bahari, M. B., Al-Qazaz, H. K., Salih, M. R., Jamshed, S. Q., \& Elkalmi, R. M. (2014). Are parents' knowledge and practice regarding immunization related to pediatrics' immunization compliance? a mixed method study. BMC pediatrics, 14(1), 20.

Alenazi, I., Alruwaili, F., Aljumayi, A., Alqahtani, A., AlGhamedi, A., Alsaad, H., .. . Fetiha, B. The Educational level and vaccination knowledge among parents in Dawadmi-Saudi Arabia, 2014.

Ali, Z., Pongpanich, S., \& Kumar, R. (2015). Effectiveness of community service model for increasing routine immunization coverage at primary healthcare facilities in a rural district of Pakistan: a quasi-experimental study. Journal of Ayub Medical College Abbottabad, 27(4), 853-857.

Animaw, W., Taye, W., Merdekios, B., Tilahun, M., \& Ayele, G. (2014). Expanded program of immunization coverage and associated factors among children age 12-23 months in Arba Minch town and Zuria District, Southern Ethiopia, 2013. BMC public health, 14(1), 464.

Antony, A., Shajan, M., Reji, J., Kale, S., Kadam, S., \& Aher, G. (2015). A study to assess the knowledge and the practices adopted by the mothers for their babies vaccinated with BCG in selected areas in Mumbai.

Asim, M., Mahmood, B., \& Sohail, M. M. (2015). INFANT HEALTH CARE; PRACTICES IN PAKISTAN: A SYSTEMATIC REVIEW. Professional Medical Journal, 22(8).

Awadh, A. I., Hassali, M. A., Al-Lela, O. Q., Bux, S. H., Elkalmi, R. M., \& Hadi, H. (2014). Does an educational intervention improve parents' knowledge about immunization? Experience from Malaysia. BMC pediatrics, 14(1), 254.

Awoh, A. B., \& Plugge, E. (2016). Immunisation coverage in rural-urban migrant children in low and middleincome countries (LMICs): a systematic review and meta-analysis. J Epidemiol Community Health, 70(3), 305-311.

Bugvi, A. S., Rahat, R., Zakar, R., Zakar, M. Z., Fischer, F., Nasrullah, M., \& Manawar, R. (2014). Factors associated with non-utilization of child immunization in Pakistan: evidence from the Demographic and Health Survey 2006-07. BMC public health, 14(1), 232.

Esposito, S., Principi, N., Cornaglia, G., \& Group, E. V. S. (2014). Barriers to the vaccination of children and adolescents and possible solutions. Clinical Microbiology and Infection, 20, 25-31.

Harvey, H., Reissland, N., \& Mason, J. (2015). Parental reminder, recall and educational interventions to improve early childhood immunisation uptake: a systematic review and meta-analysis. Vaccine, 33(25), 2862-2880.

Kaoje, A., Yahaya, M., Olayinka, R. M., Hauwau, S., Abubakar, J., \& Ambursa, A. H. (2017). Prevalence of vaccine preventable diseases and utilization of routine immunizations services by parents of under-one children in a semi-urban community of Sokoto State, Nigeria. Global Journal of Medicine and Public Health, 6(4), 10

Landoh, D. E., Ouro-Kavalah, F., Yaya, I., Kahn, A.-L., Wasswa, P., Lacle, A., . . Soura, A. B. (2016). Predictors of incomplete immunization coverage among one to five years old children in Togo. BMC public health, $16(1), 968$.

Mohamud, A. N., Feleke, A., Worku, W., Kifle, M., \& Sharma, H. R. (2014). Immunization coverage of 12-23 months old children and associated factors in Jigjiga District, Somali National Regional State, Ethiopia. BMC public health, 14(1), 865 .

Montasser, N. A. E.-H., Helal, R. M., Eladawi, N., Mostafa, E., El Rahman, F. A., Saad, M., \& Hamza, S. (2014). Knowledge, attitude and beliefs of caregivers of children below 2 years of age towards immunization. British Journal of Medicine and Medical Research, 4(14), 2757.

Murtaza, F., Mustafa, T., \& Awan, R. (2016). Determinants of nonimmunization of children under 5 years of age in Pakistan. Journal of family \& community medicine, 23(1), 32.

Shaikh, S., Memon, S., \& Ahmed, I. (2014). Impact of an IEC (Information, Education and Communication) 
intervention on key family practices of mothers related to child health in Jamshoro, Sindh. Pakistan journal of medical sciences, 30(3), 611.

Sharif, M., Daryani, A., Kia, E., Rezaei, F., Nasiri, M., \& Nasrolahei, M. (2015). Prevalence of intestinal parasites among food handlers of Sari, Northern Iran. Revista do Instituto de Medicina Tropical de São Paulo, 57(2), $139-144$.

Umarani, J. (2017). Teaching package improves mothers knowledge on vaccine preventable diseases and vaccination: a Quasi experimental study. International Journal of Research in Medical Sciences, 2(3), 976982.

Varghese, R., Swami, P., Patel, S. V., Patel, S. H., Sweta, J., Patel, V. P., \& Patel, V. (2016). Effectiveness of planned teaching programme on knowledge regarding immunization among antenatal mothers at selected villages of Waghodia Taluka. IJAR, 2(8), 157-160.

Vittappa, C. (2006). Study to assess the effectiveness of information booklet on vaccine preventable diseases among the mothers of under five children in begur primary health center Bnagalore South Karnataka. RGUHS.

Younus, M., Ijaz, S. F., \& Mateen, A. (2017). Knowledge of EPI Vaccination among Primigravida Mothers. Age, 25(57), 57. 